\title{
Methods and Tools for Creating Virtual Robots Using Self-Organization or Hierarchical Behavior in Ensuring the Security of Artificial Intelligence
}

\author{
Zarif Zafarovich Kodirov ${ }^{1}$, Sunatullo Nasriddin ogli Hojiyev², Munisa Xamza kizi Islomova ${ }^{3}$, Alisher \\ Zafarovich Kodirov ${ }^{4}$, Humoyun Ravshon ogli Ochilov ${ }^{5}$ \\ ${ }^{1,2}$ Doctoral Student, Tashkent University of Information Technologies \\ ${ }^{3,4,5}$ Master Student, Tashkent University of Information Technologies
}

\begin{abstract}
This article discusses algorithms and tools for setting up optimal control, information security, and the use of Coppeliasim technologies in artificial intelligence software and hardware. Cleverly created robots help and work for different areas of human life. What is artificial intelligence. AI methods: NLP, CV, Data Science. National Strategy for the Development of Artificial Intelligence in Uzbekistan.AI research.AI standardization. Standards in the field of artificial intelligence in all areas. Top 3 Trends in Artificial Intelligence. Uzstandart approved the first standards in the field of AI.ISO / IEC experts support proposal to develop Uzbek language standard. Development of standards in the field of quantum communications, AI and smart city The impact of artificial intelligence. Threats to the development of human civilization. Impact on the economy and business. Impact on the labor market. Wrongness of artificial intelligence. Artificial intelligence technology market. AI market in Uzbekistan. Global AI market. AI applications. Artificial intelligence technologies and solutions: a turning point.AI in decision making: today and tomorrow. Artificial intelligence in software development. Artificial intelligence to solve demographic problems. Use of AI for defense and military purposes. Use in education. Use of AI in business.
\end{abstract}

KEYWORDS: Applied Materials AMD, Artificial Intelligence, Celera, Coppeliasim, ML, Data, Global Foundries, GCT Semiconductor, IoT, Infineon, Intel Corporation, NUVIA.

\section{INTRODUCTION}

The smallest technologies that can perform the most commands in the human universe can be called small brains. Applications of AI

The areas of application of AI are quite wide and cover both technologies that are familiar to hearing, and emerging new areas that are far from mass application, in other words, this is the whole range of solutions, from vacuum cleaners to space stations. It is possible to divide all their diversity according to the criterion of key points of development.

AI Methods: NLP, CV, Data Science Natural Language (NLP) Speech Technologies. Texts: recognize, automatically translate. Speech: recognize, generate. Computer vision (CV) find, track, classify, identify objects extract data from images analyze the received information. It is applied for object recognition video analytics descriptions of the content of images and videos gesture and handwriting recognition intelligent image processing. Data Analysis extract knowledge find patterns in data predict. Use methods. Statistics econometrics. Machine learning, Deep learning.

AI is not a monolithic subject area. Moreover, some AI technologies appear as new sub-sectors of the economy and separate entities, while simultaneously serving most areas in the economy.

Microchip Technology is a leading provider of smart, connected and secure built-in management solutions. It will require easy-to-use development tools i.e. industrial robots, and a comprehensive product portfolio will allow customers to create optimal designs that reduce risk.

The idea of creating an artificial human image has long been a concern of the human mind, as evidenced by the development of technology. In the Middle Ages, people talked about the possibility of creating a human-like mechanical thinking machine, and became accustomed to executing commands through computers that humans could not do quickly. After some time, a great scientific basis for the possibility of creating artificial intelligence emerged. Nowadays, the use of microchips in the development of artificial intelligence systems is very useful. There are many examples of this. All machines work on the basis of specialized computer programs and microchips. 


\section{International Journal of Current Science Research and Review}

ISSN: 2581-8341

Volume 05 Issue 02 February 2022

DOI: 10.47191/ijcsrr/V5-i2-31, Impact Factor: 5.825

\section{Main part}

Self-organization or construction of a physical pattern using hierarchical behaviours. Make it happen.

I used mobile robots in the CoppeliaSim / V-REP scenes and mostly robots used in these labs. And I added additional features to these robot functions. My scenario is very different from the labs in this module because the internal rotation cylinders are formed by connecting the drone blades to the rotating position. A special algorithm(Figure 1) ensures serial execution. I chose to use the Lua language, which is connected to the CoppeliaSim / V-REP simulator and contains the functions and libraries I need, as this language is more closely integrated into the simulator program. Also, I am testing some modules in $\mathrm{c}++$. and Python. The work is very interesting and I learned that in the process it is a great tool for us to save the expected financial resources from redundant devices.

\section{ALGORITHM , RESULTS AND DISCUSSIONS}

Commands are being issued. Render is being placed sequentially. Cheaker is being checked and errors are being reviewed. Correct commands are being executed sequentially. You can see it in Figure 1. AI in the power industry. At the design level: improved forecasting of generation and demand for energy resources, assessment of the reliability of power generating equipment, automation of generation increase in case of a demand surge. At the production level: optimizing preventive maintenance of equipment, increasing generation efficiency, reducing losses, preventing theft of energy resources. At the promotion level: optimization of pricing depending on the time of day and dynamic billing. At the level of service delivery: automatic selection of the most profitable supplier, detailed consumption statistics, automated customer service, energy optimization based on customer habits and behavior.

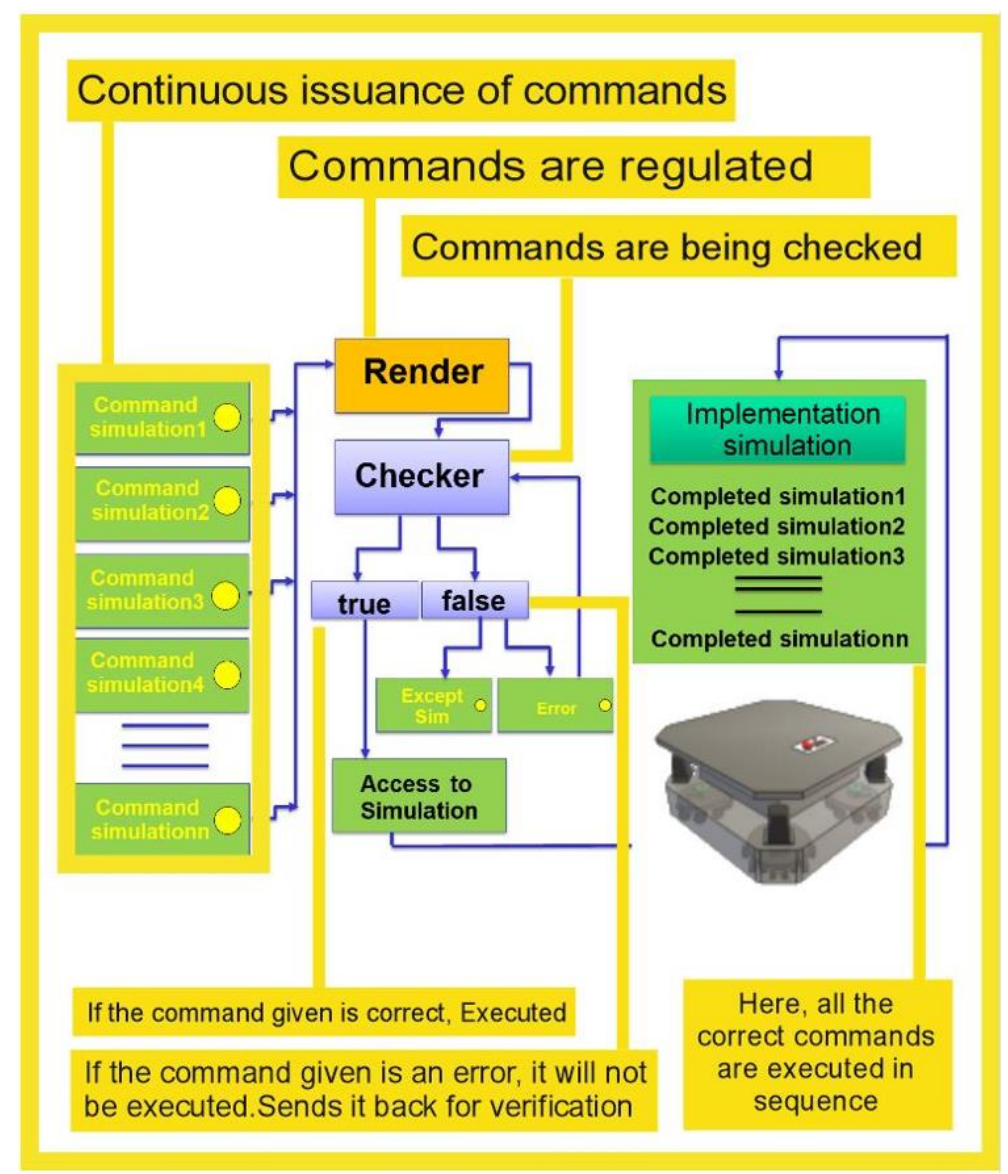

Figure 1. Shows how the program code works and is interpreted, has the correct structure, and uses descriptive variable names. adheres strictly to programming practices and you can check it. The main element of the core output figure. 


\section{International Journal of Current Science Research and Review}

ISSN: 2581-8341

Volume 05 Issue 02 February 2022

DOI: 10.47191/ijcsrr/V5-i2-31, Impact Factor: 5.825

IJCSRR@ 2022

Www.ijjesrr.org

The parameter of the function of the main element of the core output.Core output line main coppeliasim figure. The parameter for transmitting information from the system to the main function.

In this case, the virtual robot moves on the basis of a certain function. It is given commands through special array elements. The work is carried out on this basis.

\section{MATHEMATICS MODEL}

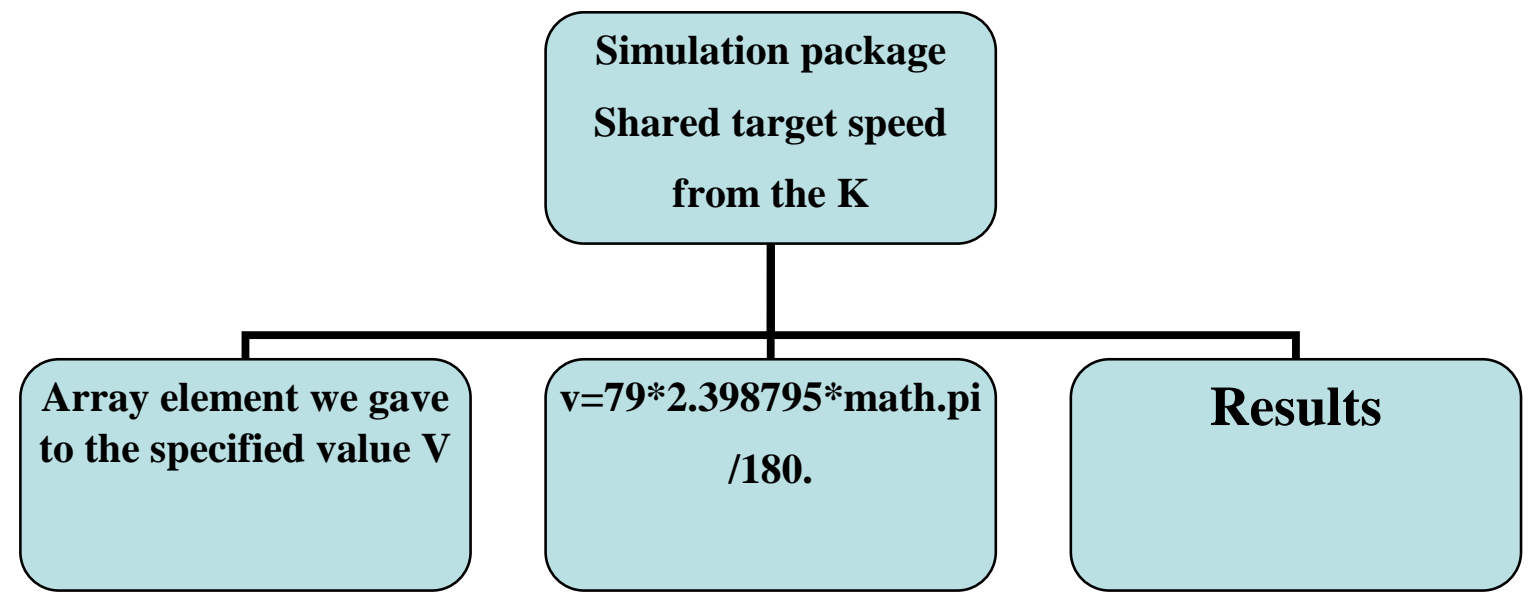

Model 1

The state in which the work is performed on the basis of a special formula. A part of a virtual robot taken from a program model 1.

\section{GRAPHICS COPPELIASIM MODEL}

Can you imagine the next decade? Machine learning is nothing more than the implementation of artificial intelligence, which allows systems to learn and improve past experiences without precise programming at the same time. It just means perfection and high development. AI in manufacturing: At the design level: improve the efficiency of new product development, automated supplier evaluation and analysis of requirements for spare parts and parts. At the production level: improving the process of executing tasks, automating assembly lines, reducing the number of errors, reducing the delivery time of raw materials. At the promotion level: forecasting the volume of support and maintenance services, pricing management.

At the level of service delivery: improving fleet route planning, demand for fleet resources, improving the quality of training of service engineers.

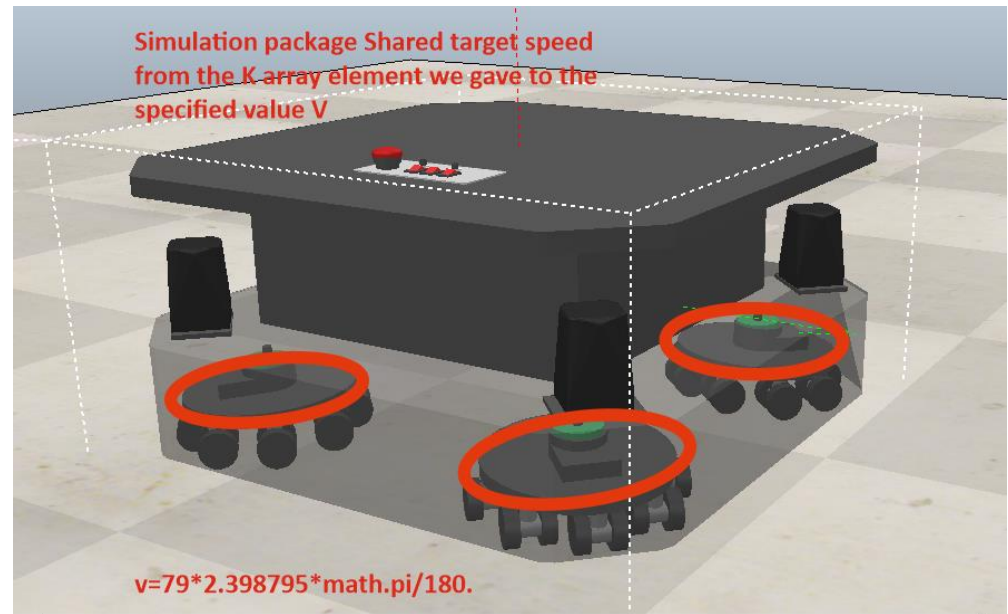

GRAPHICS COPPELIASIM MODEL 1 


\section{International Journal of Current Science Research and Review}

ISSN: 2581-8341

Volume 05 Issue 02 February 2022

DOI: 10.47191/ijcsrr/V5-i2-31, Impact Factor: 5.825

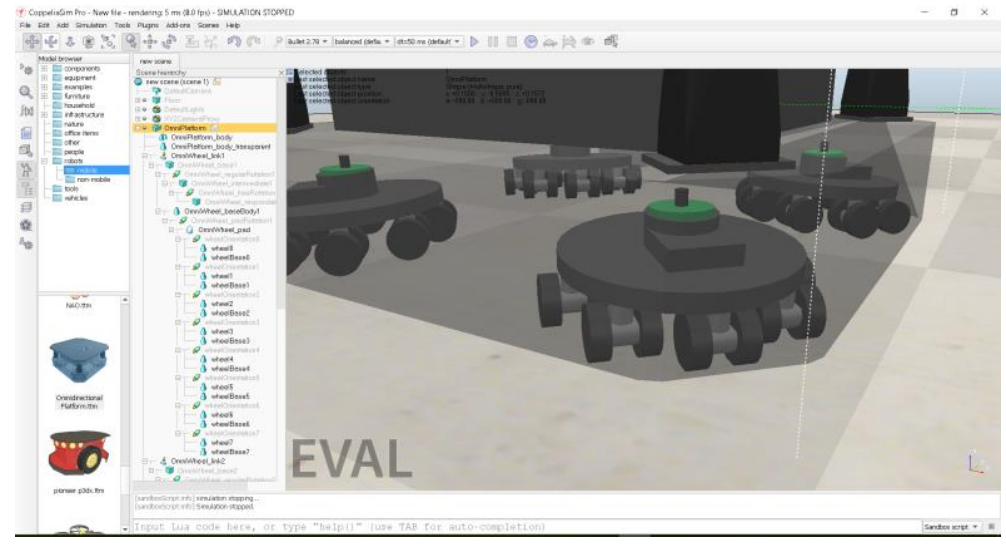

GRAPHICS COPPELIASIM MODEL 2

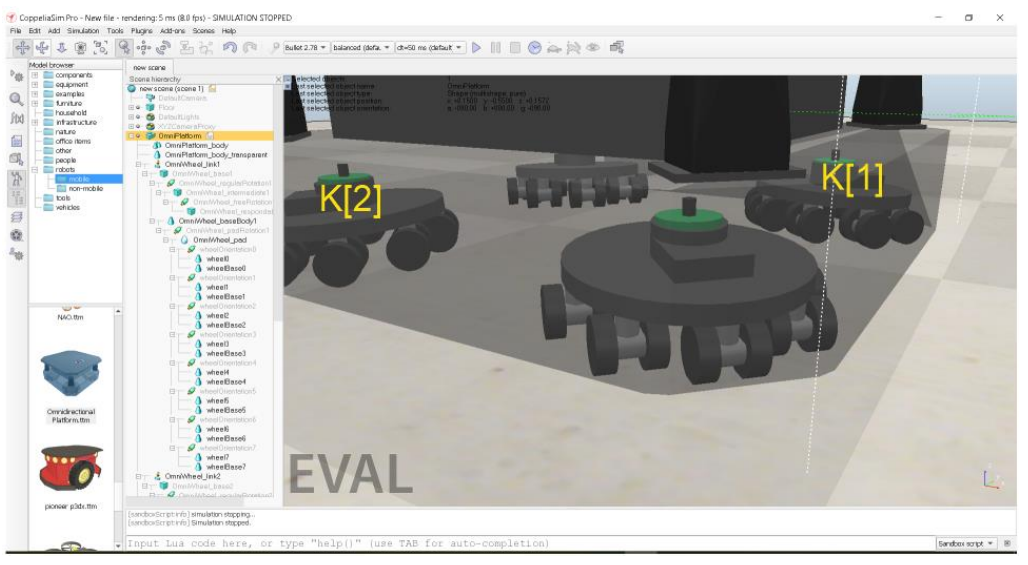

GRAPHICS COPPELIASIM MODEL 3

It is the process of tracking data models, gathering relevant data, and making effective decisions for the future of any organization. Machine learning makes it easy to analyze large amounts of data, usually with quick and accurate results to get useful benefits and opportunities.

A. Mathematically simple model data verification algorithms Figure 1

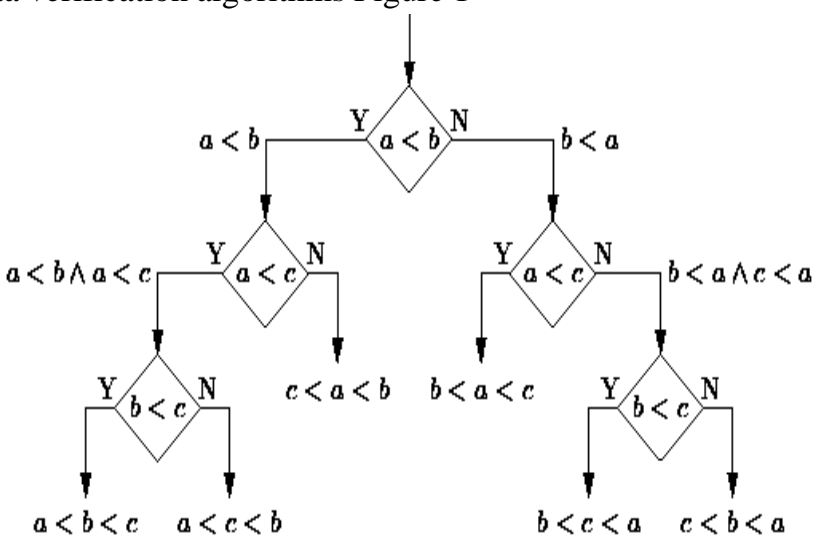

B.Neural network mathematical graphical analysis algorithm Input Data a;

Layers Data b; Output Data c; 


\section{International Journal of Current Science Research and Review}

ISSN: 2581-8341

Volume 05 Issue 02 February 2022

DOI: 10.47191/ijcsrr/V5-i2-31, Impact Factor: 5.825

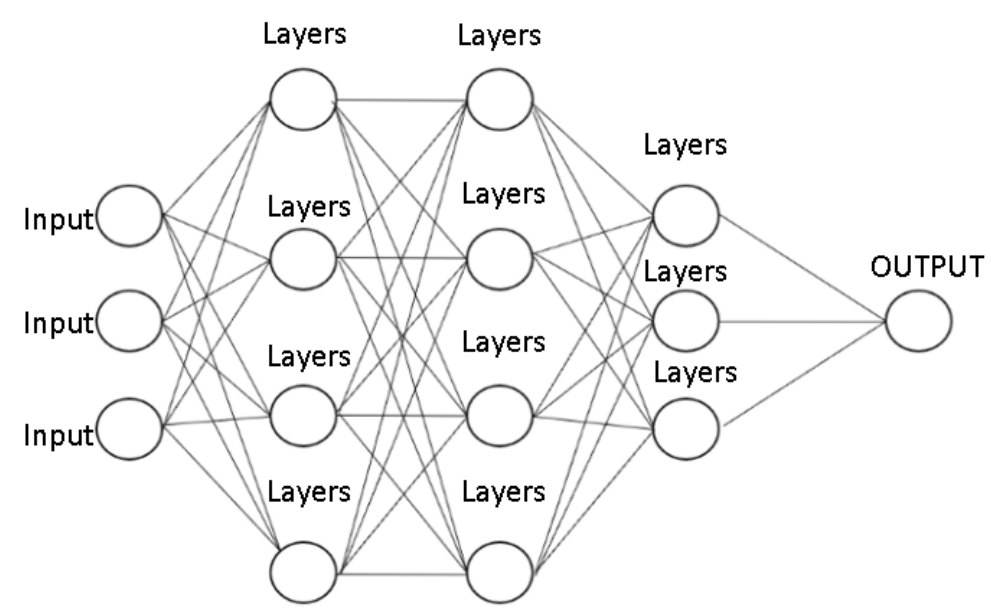

Type of eSIM technology in robotic systems

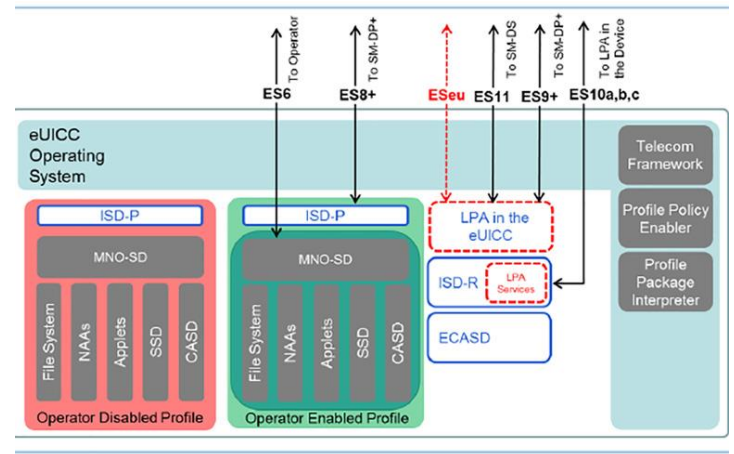

Coppeliasim is a standard developed by GSMA, which allows you to store multiple carrier profiles on a single built-in electronic device (chip) and connect devices to a mobile connection without physical SIM cards.

\section{PROGRAMMING TOOLS USED TO CREATE A PROGRAM}

\section{Conclusions}

The software is developed in Visual Studio $2022 \mathrm{C}$ \# WinForms environment. We used eSIM technology and raspberry in our program. We used ESP8266 WiFi Transceiver ESO32 GPIOs for IoT technologies in control systems Library Collection:

- For consideration in the treatment of ESP32 problems

- How to implement ESP32 access point (AP) for web server

- ESP32 Static / Fixed IP Address

Once all content is digitized, it will be connected to a machine learning system that will analyze the records and decide which cases use the most credible evidence. This should reduce the time it takes to process cases and solve past and future crimes from weeks to days. Artificial intelligence will distribute cases according to their "solvability" and indicate the possible results of the DNA examination. Then it is planned to automate the analysis in other areas of forensic science and perhaps even cover data in areas such as social sciences and testimony. In addition, according to one of the developers of the system Jeroen Hammer API functions for partners may be released in the future. AI not only improves customer interactions, but also serves as an important source of information for brands. Since the information is provided directly by the client, this data is more useful than information obtained through cookies or browsing history.

When combined with other data, such as a user's social media profile and demographics, brands will be able to better understand customer trends, emotions, and moods and adjust product management strategies accordingly. 


\section{International Journal of Current Science Research and Review}

ISSN: 2581-8341

Volume 05 Issue 02 February 2022

DOI: 10.47191/ijcsrr/V5-i2-31, Impact Factor: 5.825

IJCSRR@ 2022

www.ijesrr.org

\section{REFERENCES}

1. Archer J, Fotheringham N, Symmons M, Corben B (2008) The impact of lowered speed limits in urban and metropolitan areas (Report \#276). Monash University Accident Research Centre (www.monash.edu.au/miri/research/reports/muarc276.pdf)

2. Arkin RC (2009) Governing lethal behavior in autonomous robots. Taylor and Francis, Boca Raton

3. Arkin RC (2010) The case of ethical autonomy in unmanned systems. J Mil Ethics 9(4):332-341

4. Arth M (2010) Democracy and the common wealth: breaking the stranglehold of the special interests. Golden Apples Media, DeLand

5. Asaro PM (2008) How just could a robot war be? In: Briggle A, Waelbers K, Brey Ph (eds) Current issues in computing and philosophy. IOS Press, Amsterdam, pp 50-64

6. Aldrich FK (2003) Smarthomes: past, present and future. In: Harper R (ed) Inside the smart home. Springer, London, pp 17-39

7. Alley R (2013) The drone debate. Sudden bullet or slow boomerang (discussion paper nr. 14/13). Centre for Strategic Studies, Wellington

8. Akrich M (1992) The description of technical objects. In: Bijker W, Law J (eds) Shaping technology/building society: studies in sociotechnical change. MIT Press, Cambridge, pp 205-224

9. Bacevich AJ, Cohen EA (2001) War over Kosovo: politics and strategy in a global age. Columbia University Press, Columbia

10. Birk A, Kenn H (2002) RoboGuard, a teleoperated mobile security robot. Control Eng Pract 10(11):1259-1264

11. Broggi A, Zelinsky A, Parent M, Thorpe CE (2008) Intelligent vehicles. In: Siciliano B, Khatib O (eds) Springer handbook of robotics. Springer, Berlin, pp 1175-1198

12. Borenstein J, Pearson Y (2010) Robot caregivers: harbingers of expanded freedom for all? Ethics Inf Technol 12(3):277288

13. Breazeal C (2003) Toward sociable robots. Robot Auton Syst 42(3-4):167-175

14. Breazeal C, Takanski A, Kobayashi T (2008) Social robots that interact with people. In: Siciliano B, Khatib O (eds) Springer handbook of robotics. Springer, Berlin, pp 1349-1369

Cite this Article: Zarif Zafarovich Kodirov, Sunatullo Nasriddin ogli Hojiyev, Munisa Xamza kizi Islomova, Alisher Zafarovich Kodirov, Humoyun Ravshon ogli Ochilov (2022). Methods and Tools for Creating Virtual Robots Using SelfOrganization or Hierarchical Behavior in Ensuring the Security of Artificial Intelligence. International Journal of Current Science Research and Review, 5(2), 559-564 